\title{
Total Elbow Arthroplasty: Clinical Outcomes, Complications, and Revision Surgery
}

\author{
Jae-Man Kwak, MD, Kyoung-Hwan Koh, MD*, In-Ho Jeon, MD* \\ Department of Orthopedics, Biomechanics Laboratory, Mayo Clinic, Rochester, MN, USA, \\ ${ }^{*}$ Department of Orthopedic Surgery, Asan Medical Center, University of Ulsan College of Medicine, Seoul, Korea
}

\begin{abstract}
Total elbow arthroplasty is a common surgical procedure used in the management of advanced rheumatoid arthritis, posttraumatic arthritis, osteoarthritis, and unfixable fracture in elderly patients. Total elbow prostheses have evolved over the years and now include the linked, unlinked, and convertible types. However, long-term complications, including infection, aseptic loosening, instability, and periprosthetic fracture, remain a challenge. Here, we introduce each type of implant and evaluate clinical outcomes and complications by reviewing the previous literature.
\end{abstract}

Keywords: Arthroplasty, Replacement, Elbow, Complications, Reoperation, Treatment outcome

Total elbow replacement was originally developed to manage end-stage rheumatoid arthritis (RA). ${ }^{1)}$ Its indications have expanded to include unfixable comminuted fracture, osteoarthritis (OA), and posttraumatic arthritis. ${ }^{2-10)}$ Less commonly, it is indicated for hemophilic arthropathy, juvenile idiopathic arthritis, and primary or metastatic tumor. Despite the increasing use, however, long-term complications, such as infection, aseptic loosening, instability, and periprosthetic fracture, remain a challenge. ${ }^{11-16)} \mathrm{Be}-$ cause it is a relatively rare procedure, most surgeons have less experience with total elbow arthroplasty (TEA) than hip and knee arthroplasty, and few long-term outcome data are available. Therefore, to avoid iatrogenic errors, surgeons should carefully review the previous literature on TEA. In this review article, we summarize the prosthesis designs and outcomes of TEA and management of patients undergoing revision surgery.

Received May 2, 2019; Accepted July 22, 2019

Correspondence to: In-Ho Jeon, MD

Department of Orthopedic Surgery, Asan Medical Center, 88 Olympic-ro

43-gil, Songpa-gu, Seoul 05505, Korea

Tel: +82-2-3010-3536, Fax: +82-2-3010-3536

E-mail: jeonchoi@gmail.com

\section{TYPES OF IMPLANTS AND BIOMECHANICS}

Implant designs for TEA have evolved in recent decades since 1972 when Dee ${ }^{1)}$ first reported on the outcomes of TEA using a hinged implant in RA patients. According to a recent systematic review, 19 specific designs have been introduced. ${ }^{17)}$ In the present study, we report on four popular implant systems among more than 10 types of implants. $^{14)}$

\section{Unlinked Design (Kudo Type 5 System)}

The Kudo prosthesis was first reported in $1990^{18)}$ and is one of the most popular unlinked TEA designs used to treat end-stage RA of the elbow. ${ }^{19)}$ Theoretically, unlinked TEA has no mechanical connection between the humeral and ulnar components and thus has advantages of nearnormal elbow kinematics and preservation of bone stock. The unlinked design was established to overcome loosening of the hinge prosthesis. Unlinked TEA is appropriate only for patients with limited bone loss or limited deformity and good ligament function. Nonconstrained TEAs have low intrinsic stability and rely on soft-tissue balancing. The primary stabilizers of nonconstrained TEA are the medial and lateral collateral ligaments, ${ }^{20)}$ and the posterior capsule and surrounding muscles function as secondary stabilizers. This is because postoperative instability is a major complication of unlinked prostheses. The 
Kwak et al. Total Elbow Arthroplasty: Clinical Outcomes, Complications, and Revision Surgery

Clinics in Orthopedic Surgery • Vol. 11, No. 4, $2019 \bullet$ www.ecios.org

concept and objective of unlinked TEA are to share the loading stress on the bone-implant interface with the surrounding tissues. Kodama et al. ${ }^{21,22)}$ reported survival rates of $87.8 \%$ at 5 years and $70.7 \%$ at 10 years, and the most common complication was aseptic loosening.

\section{Linked Semiconstrained Design (Coonrad-Morrey)}

The Coonrad-Morrey Total Elbow (Zimmer, Warsaw, IN, USA) is a second-generation linked semiconstrained design featuring a central cylindrical bearing and two side bearings. The linked semiconstrained implant is one of the most frequently used devices for TEA. It allows some varus-valgus motion, reducing stress concentration on the bone-cement interface. ${ }^{20,23-25)}$ The implant permits $7^{\circ}-10^{\circ}$ of varus-valgus movement and $7^{\circ}-10^{\circ}$ of axial rotation of the knee. Adding an anterior flange to the humeral component also protects the bone-cement interface from stress forces. The central locking pin was redesigned in 1996. The ulnar component was modified from a beaded surface to a polymethylmethacrylate-precoated surface in 1992, but it was turned back to have a beaded surface in $2001 .^{26-28)}$ This design has been used to treat conditions including RA, degenerative arthritis, and trauma reconstruction, and satisfactory outcomes have been reported with longterm follow-up. ${ }^{25,29-36)}$ However, aseptic loosening together with bushing wear is a leading complication of implant failure, and reducing the complication rate remains a challenge. ${ }^{13,20,24,37)}$

\section{Semiconstrained Condylar-Bearing Design (Discovery Elbow System)}

The Discovery Elbow System (Biomet LLC, Warsaw, IN, USA) is a hemispherical linked prosthesis designed to decrease complications associated with a semiconstrained prosthesis, especially bushing wear. ${ }^{26)}$ Its minimally constrained design allows a close match of the articular surfaces, avoids the use of a true hinge, and anatomically reproduces the axis of elbow motion. Its floppy hinge allows for $6^{\circ}-8^{\circ}$ of varus-valgus and rotational motion; the increased contact area between the cobalt-chrome and ultra-high-molecular-weight polyethylene prevents the occurrence of edge loading and reduces stresses within the polyethylene TEA. Moreover, the design enables posterior access during bushing revision. ${ }^{38-40)}$

\section{Convertible Design (Latitude System)}

More recently, convertible TEAs (Latitude Tornier implant system; Tornier, Montbonnot-Saint-Martin, France) allow surgeons to choose between a nonconstrained and semiconstrained prosthesis. ${ }^{41,42)}$ If the surgeon has concerns regarding collateral ligament insufficiency or implant stability, a semiconstrained hinge can be created by applying a modular component to the ulnar prosthesis. Two-year follow-up outcome of convertible TEA was comparable with that in historical controls; however, no long-term survival data have been reported. ${ }^{41,42)}$

\section{CLINICAL OUTCOMES}

\section{Overall Outcomes and Survival Rates}

A recent systematic review reported promising overall clinical outcomes for pain relief, restoration of function, and range of motion. Welsink and the colleagues ${ }^{17,43)}$ systematically analyzed 73 articles and reported overall outcomes: the weighted mean American Shoulder and Elbow Surgeons score was 66.7 points, patients with RA had a weighted mean Mayo Elbow Performance Score (MEPS) of 85.3 points, and those with trauma or fracture had a weighted mean MEPS of 84.1 points. In addition, they found that approximately $60 \%$ of the patients were painfree at the latest follow-up (mean, 6.3 years). The weighted mean difference of the flexion angle was $129^{\circ}$, and the weighted mean extension lag was $30^{\circ}$. The weighted mean supination was $66^{\circ}$, and the weighted mean pronation was $71^{\circ}$. The complication rate was $19.1 \%$ (at 5.9 years) for the linked prosthesis and $26.5 \%$ (at 8.2 years) for the unlinked prosthesis (Table 1). ${ }^{17,43)}$ Using data from the Norwegian Arthroplasty Register from 1994 to 2016, Krukhaug et al. ${ }^{44)}$ reported that overall outcomes and survival rates of TEA

\section{Table 1. Indication and Complication Rate of TEA}

\begin{tabular}{lcc}
\hline \multicolumn{1}{c}{ Variable } & Linked TEA & Unlinked TEA \\
\hline No. of articles & 37 & 28 \\
\hline No. of elbows & 2,087 & 2,273 \\
\hline Weighted follow-up (yr) & 5.9 & 8.2 \\
\hline Indication & & \\
\hline Rheumatoid arthritis & 1,106 & 2,149 \\
\hline Fracture & 571 & 401 \\
\hline Posttraumatic osteoarthritis & 229 & 19 \\
\hline Osteoarthritis & 31 & 27 \\
\hline Other & 150 & 64 \\
\hline No. of complications (\%) & $398(19.1)$ & $602(26.5)$ \\
\hline No. of revisions (\%) & $273(13.1)$ & $364(16.0)$ \\
\hline
\end{tabular}

TEA: total elbow arthroplasty. 
Kwak et al. Total Elbow Arthroplasty: Clinical Outcomes, Complications, and Revision Surgery

Clinics in Orthopedic Surgery • Vol. 11, No. 4, $2019 \bullet$ www.ecios.org

demonstrated overall 5-, 10-, 15-, and 20-year survival rates of $92 \%, 81 \%, 71 \%$, and $61 \%$, respectively.

\section{Rheumatoid Arthritis}

The annual incidence of TEAs performed for inflammatory arthritis is decreasing, which is probably due to the efficacy of disease-modifying antirheumatic drugs. ${ }^{14,17)}$ Despite this progress in the medical treatment of RA, severe cases are still the most common indications for TEA after failed medical treatment. A mean patient satisfaction of 9.2 out of a possible 10 points was reported in a study by Hildebrand et $\mathrm{al}^{45)}$ on the functional outcome of patients with inflammatory arthritis who underwent TEA. A study by Mansat and the colleagues ${ }^{29,33)}$ demonstrated that treatment outcome after TEA for RA with a minimum 2-year follow-up had a $97 \%$ survival rate (95\% confidence interval [CI], $83.6 \%$ to $99.6 \%)$ at 5 years and $85 \%$ (95\% CI, $68.3 \%$ to $93.7 \%)$ at 10 years. At an average of 7 years of follow-up (range, 2-16 years), the mean MEPS was 91 points (range, 55-100 points), and the shortened version of the Disabilities of the Arm, Shoulder and Hand score was 34 points (range, 0-75 points). A significant improvement was seen in the MEPS and in all range of motion scores at the latest follow-up in comparison to preoperative values.

\section{Distal Humerus Fracture}

Because many surgeons currently select TEA to manage comminuted distal humerus fracture, the indications for TEA for trauma-related disease have expanded. ${ }^{5,7-9,46-50)}$ However, the choice of treatment remains debatable in younger patients because long-term outcomes are not available owing to the paucity of data. ${ }^{49,50)}$ Rajaee et al. ${ }^{9)}$ compared TEA with open reduction and internal fixation (ORIF) using data obtained from the Nationwide Inpatient Sample for 2002-2012. ${ }^{51)}$ The data demonstrated that the annual frequency of TEA increased 2.6-fold in elderly patients with distal humerus fractures, and TEA is the preferred treatment alternative to ORIF in elderly patients with complex distal humerus fractures that are not amenable to stable fixation. In 44 TEAs after distal humeral fracture, Barco et al. ${ }^{52)}$ reported that the mean visual ana$\log$ scale score for pain was 0.6 , the mean flexion was $123^{\circ}$, and the mean loss of extension was $24^{\circ}$. The mean MEPS was 90.5 points, with three patients scoring $<75$ points.

\section{Posttraumatic Arthritis}

TEA could be a treatment option for advanced posttraumatic arthritis, but the outcome is not satisfactory when compared to other indications. ${ }^{9,17,31,53-55)}$ Patients typically have $>1$ previous surgery with scars and severe limited range of motion due to soft-tissue contraction. This disadvantage leads to difficulty in approaching and managing the soft tissue. The worse prognosis was seen in patients who developed traumatic arthritis after fracture than in patients with inflammatory arthritis. ${ }^{44,56,57)}$ Hildebrand et al. ${ }^{45)}$ also reported the functional outcome of TEA in patients with posttraumatic arthritis. The mean score (and standard deviation) on the Mayo Elbow Performance Index was significantly higher for the group with inflammatory arthritis (90 \pm 11 points) than for the group with a traumatic or posttraumatic condition (78 \pm 18 points) at the latest follow-up. Younger patients with advanced posttraumatic arthritis who are not well managed present a difficult dilemma. Celli and Morrey ${ }^{58)}$ reported a series of 55 TEAs performed in patients aged $<40$ years with a mean 7.5-year follow-up. Thirty-six patient (65\%) were considered to be excellent and fifteen (27\%) were good. Similarly, Park et al. ${ }^{59)}$ reported a series of 23 TEAs performed in patients aged $<40$ years with a mean follow-up of 10 years. Despite the reported favorable outcomes, however, $25 \%$ of elbows developed complications, with $22 \%$ requiring reoperation.

\section{Primary OA}

Because the elbow is not a weight-bearing joint, the incidence of primary $\mathrm{OA}$ is rarer than that in other joints. The incidence is higher in the overused upper extremities (in manual laborers, throwing athletes, wheelchair-assisted individuals). Patients with primary OA typically have higher functional demands and capabilities than those with inflammatory arthritis. ${ }^{60)}$ Thus, it is critical to communicate with the patient regarding postoperative management, with the surgeon stressing that the risk of complications could increase if the patient continues to have the same habitual pattern of elbow use. Schoch et al. ${ }^{10)}$ reported satisfactory outcomes; however, extension gain was not always achieved. Complications occurred in a large number of elbows, but the incidence of mechanical failure was low. The MEPS for 13 elbows without mechanical failure averaged 81.5 points (range, $60-100$ points).

\section{COMPLICATIONS}

The increase in complications of revision TEA parallels the increase in primary TEA. ${ }^{14,44,49}$ It is well known that survival in TEA is substantially longer in patients with inflammatory arthritis than in those with trauma-related indications. ${ }^{45,55)}$ An increased risk of complications is also seen in patients with young age, obesity, smoking, and high comorbidity. ${ }^{43,50,58,61-64)}$ Linked arthroplasties tend to 
require more revisions due to polyethylene wear, whereas more revisions are performed in cases with unlinked prostheses due to instability and dislocations. . $^{17,19,23,43,44,65)}$ Infection, aseptic loosening, and periprosthetic fracture are the most concerning common complications primarily requiring revision surgery.

\section{Periprosthetic Joint Infection}

Even with modern surgical techniques and antibiotic prophylaxis, infection remains one of the leading complications of TEA, with reported rates ranging from $1 \%$ to $12.5 \%{ }^{43,61,66-68)}$ While there is a consensus on and greater understanding of the management of hip and knee periprosthetic joint infection (PJI), ${ }^{67-71)}$ few studies have evaluated the management of elbow PJI after TEA because of its rarity. However, it is generally understood that the elbow is susceptible to infection owing to the lack of soft-tissue covering from skin to bone. ${ }^{66,70,72-74)}$ Therefore, the surgeon must take care in every step of the surgical process including patient selection, aseptic surgical conditioning, and frozen sectioning of suspicious tissue before performing the implantation procedure to reduce or prevent the risk of infection. In the patient selection stage, the surgeon should be aware of the risk of high comorbidity with diabetes. ${ }^{62,73,75-77)}$ Several studies have reported a strong correlation between infection and comorbidity with TEA. ${ }^{61,66,73,78,79)}$ Even after the surgery, preventing infection requires general control of the comorbidities. Although a consensus is not fully established, two-stage revision surgery is commonly recommended. ${ }^{79-81)}$ Zmistowski et al. ${ }^{82)}$ reported that two-stage revision led to a decreased rate

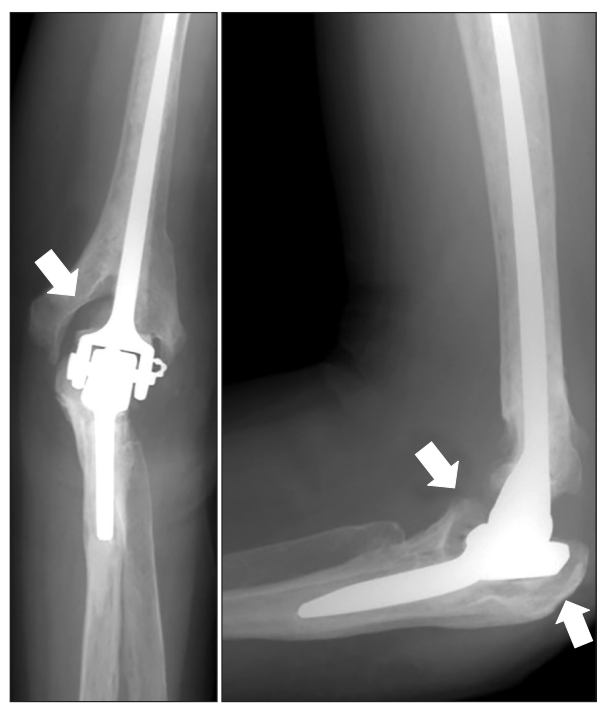

Fig. 1. Transmission of nonanatomic force results in stress shielding at the humeral condyles and olecranon, leading to bone resorption (arrows). of recurrent $\mathrm{PJI}$ and a $50 \%$ success rate over 3 years, and they recommended a prosthesis-free interval of at least 3 months. The most common pathogen was Staphylococcus aureus. ${ }^{61,68,70,72,74,83-86)}$

\section{Aseptic Loosening}

Aseptic loosening is one of the most common causes of revision surgery. ${ }^{14-17,87)}$ Stress shielding at the elbow is applied to determine the incidence of osteolysis around the implant and loosening. As Wolff's law states, bone will adapt to the loads under which it is placed. If loading on a bone increases, the bone will remodel over time and become stronger. Conversely, if loading decreases, the bone will become less dense and weaker due to the lack of stimulus required for continued remodeling. In TEA, the transmission of nonanatomic force results in stress shielding at the humeral condyles and olecranon, leading to progressive bone resorption (Fig. 1)..$^{26,37,88,89)}$ This bone resorption increases the moment of force on the arm between the hinge and the site where the stem transfers most of its load, which not only predisposes to loosening of the stem but also increases the likelihood of arthroplasty failure due to polyethylene wear, mechanical failure, or periprosthetic fracture. ${ }^{11,20,26,37,49,88,89)}$ Loose stems are amenable to revision TEA generally using a longer stem, with bone grafting performed if indicated. ${ }^{20,88,90)}$ King et al. ${ }^{91)}$ reported a series of 31 patients who underwent revision TEA due to aseptic loosening with a mean 6-year follow-up. The mean MEPS was 87 , and the mean flexion-extension arc was $>100^{\circ}$.

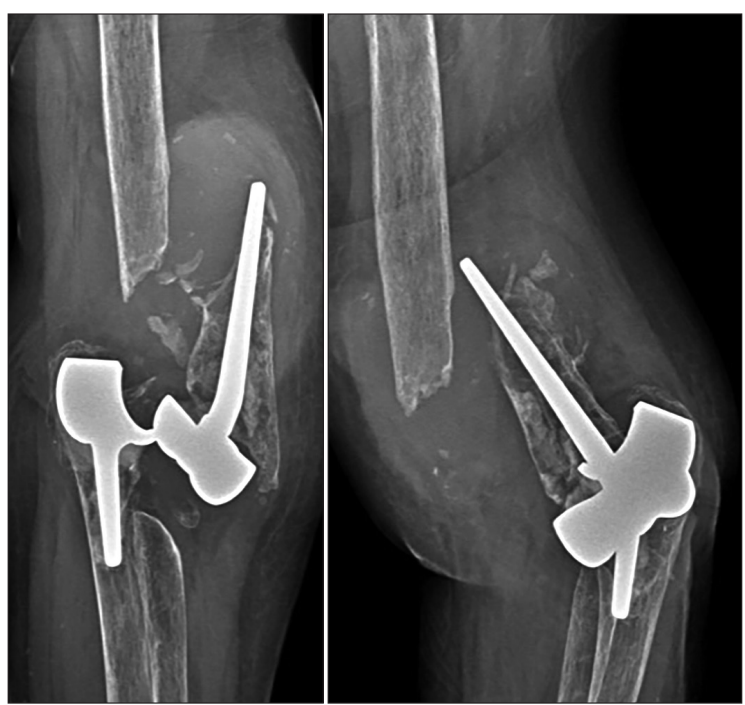

Fig. 2. Osteoporotic periprosthetic fracture due to a fall injury after unlinked total elbow arthroplasty. 


\section{Periprosthetic Fracture}

Periprosthetic fractures are the third most common cause of failure and pose difficulty for revision. ${ }^{65)}$ Although some of the principles used in treating periprosthetic hip and knee fractures can be applied to the elbow, some differences must be considered to provide the best possible treatment. ${ }^{92)}$ Because the upper extremity has smaller bones with less bone stock, management of bone defects is critical. Bone stock in both the ulna and the humerus is limited, and thus when fracture occurs, revision surgery can be challenging. Inadequate bone stock is a commonly encountered problem, particularly in patients with osteoporosis (Fig. 2). Cortical strut allograft augmentation is a recommended technique for revision in patients with poor or weak bone stock. A study has reported that periprosthetic humeral fractures associated with a loose humeral component can be effectively treated with revision elbow arthroplasty and strut allograft augmentation (Fig. 3). ${ }^{92)}$

\section{Triceps Insufficiency}

Triceps insufficiency can commonly occur after a failed surgical reattachment, particularly when tendon quality is poor or a traumatic rupture of the tendon is present. In recent systematic reviews, the rate of triceps insufficiently was between $0.4 \%$ and $2.4 \%$ after TEA using various triceps-detaching approaches. ${ }^{93,94)}$ In an effort to reduce the risk of postoperative triceps weakness and rupture, a triceps-sparing approach has been applied for primary TEA.

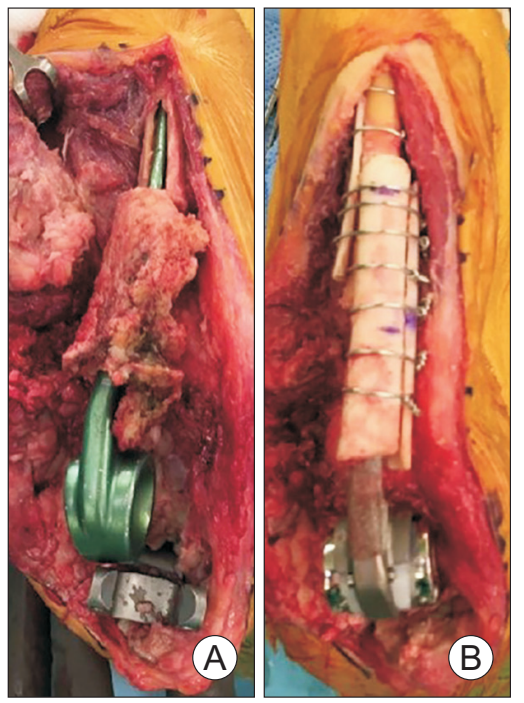

Fig. 3. (A, B) Strut graft augmentation is typically required after nonviable bone extraction. The graft must be long enough to span the fracture site and allow sufficient fixation of both the proximal and distal fragments. Cancellous bone from the humeral head allograft can be morselized for later use.
In the setting of primary TEA, several studies suggest that a triceps-sparing approach leads to fewer postoperative triceps ruptures as well as better postoperative range of motion and extension torque. ${ }^{1794)}$ Dachs et al. ${ }^{95)}$ compared triceps-sparing and triceps-detaching approaches for primary TEA: the rate of postoperative triceps rupture was $15.2 \%$ in the triceps-detaching group but the rupture was not observed in the triceps-sparing group. Solarz et al. ${ }^{96)}$ compared the triceps-sparing with triceps-detaching approaches and reported that functional strength and Disabilities of the Arm, Shoulder and Hand scores were significantly higher in the triceps-sparing group. Arc of motion, visual analog scale, and MEPS were similar between the triceps-sparing and triceps-detaching groups.

\section{Bushing Wear}

Goldberg et al. ${ }^{89)}$ reported that multimodal wear in total elbow replacements can lead to osteolysis, aseptic loosening, and prosthetic and periprosthetic fracture, necessitating revision surgery. Polyethylene wear and damage, as well as unintended metal-on-metal wear, contribute to the periprosthetic particulate burden, which is probably pathogenic in these processes. Lee et al. ${ }^{97)}$ suggested that one of the reasons for a component stem fracture after TEA seems to be fatigue failure at or near the junction between an unsupported stem and well-fixed stem. This area of unsupported stem develops as a result of osteolysis caused by bushing wear. It was emphasized that the solution for component fractures requires a solution for bushing wear.

\section{Other Complications}

Other serious complications after TEA include wound breakage, especially round the olecranon. Rhee et al. ${ }^{88)}$ reported that under unfavorable soft-tissue conditions, performing soft-tissue reconstruction with TEA provides satisfactory functional improvement and pain relief. The two-stage surgery provided a lower rate of wound complication and better elbow function than the one-stage surgery, which led to high patient satisfaction postoperatively. Development of ulnar nerve lesions is a significant complication after TEA, with potentially debilitating consequences. The outcomes of unlar nerve release with different techniques have been reported. Dachs et al. ${ }^{98)}$ reported on transposition versus in situ release: of the four patients who underwent transposition, two had postoperative ulnar nerve symptoms; in the in situ release group, the incidence of postoperative ulnar nerve symptoms was $5 \%(4 / 78)$. 
Kwak et al. Total Elbow Arthroplasty: Clinical Outcomes, Complications, and Revision Surgery

Clinics in Orthopedic Surgery • Vol. 11, No. 4, $2019 \bullet$ www.ecios.org

\section{REVISION TEA}

Types of TEA failure can be classified as infected and non-infected based on serologic markers, imaging, and intraoperative histology. ${ }^{20,23,61,99)}$ Therefore, revision TEA should be determined on the basis of the type of failure. In the infected type of failure, infectious foci should be surgically removed by extracting the implant, and this should be followed by reimplantation in addition to treatment with systemic antibiotics. ${ }^{23,70,72,79,83)}$ In contrast, the non-infected type should be treated by addressing the mechanical problems at the implant-bone or implant-implant interface. ${ }^{65,81,90,92,100-102)}$ Therefore, understanding the pathological mechanism of failure is critical when performing revision surgery and managing complications of TEA. Typically, two different surgical techniques are performed after the diagnosis. Two-stage revision surgery is usually indicated in patients with deep periprosthetic infection, whereas patients without signs suggesting infection, based on the Musculoskeletal Infection Society standards, ${ }^{67,70)}$ undergo single-stage revision surgery. If one of the components is stable, the type of implant that matches the original implant is chosen.

\section{Single-Stage Revision Surgery for Non-Infectious Causes}

After joint exposure, the remaining bone stock and the quality of the soft tissues are carefully inspected, which is followed by sharp subperiosteal release of the collateral ligament structures from the medial and lateral epicondyles. The preexisting components are meticulously removed to avoid further injury to the bones. Removing as much of the cement as possible from the medullary canal is required; however, tightly adhered cement can be left in place if it does not interfere with the implantation of the revision stem. Bone loss is managed with either cement or shortening of the humerus or ulna. In the case of epi-
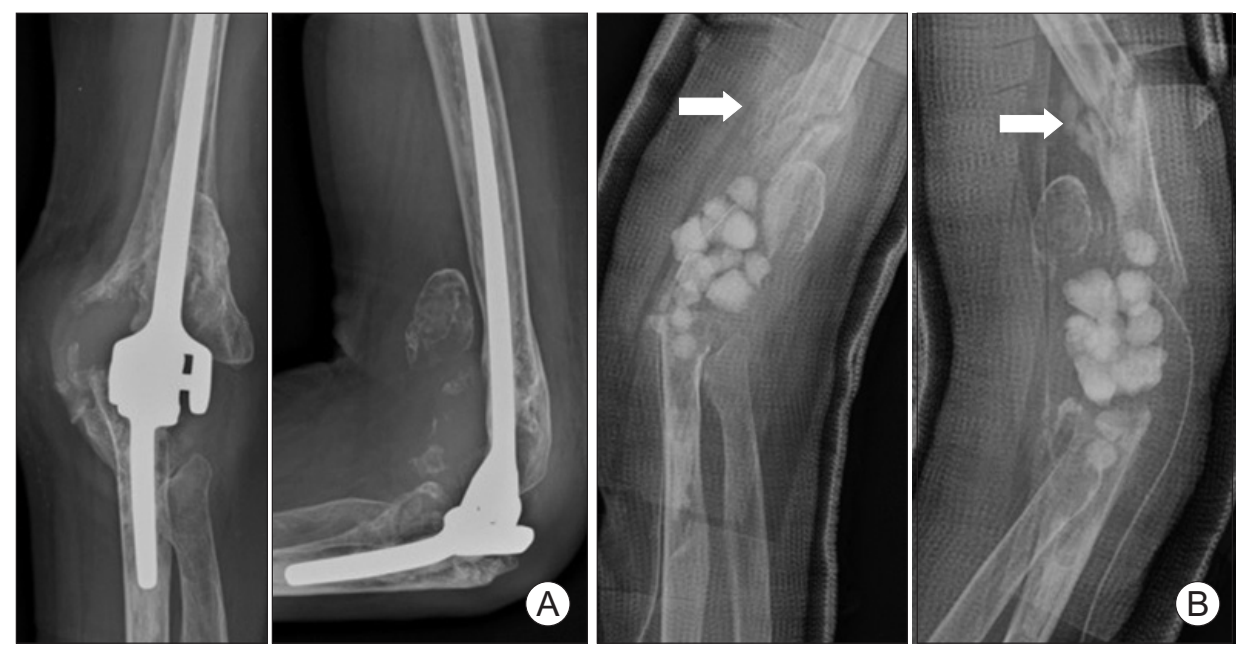

Fig. 4. First stage of revision surgery. (A) Chronic deep infection. Partial absoprtion of the distal humerus and proximal ulna, caused by chronic infection and polyethylene wear. (B) Implant removal and insertion of an antibiotic cement spacer. The fracture occurred during removal of the cement (arrows).
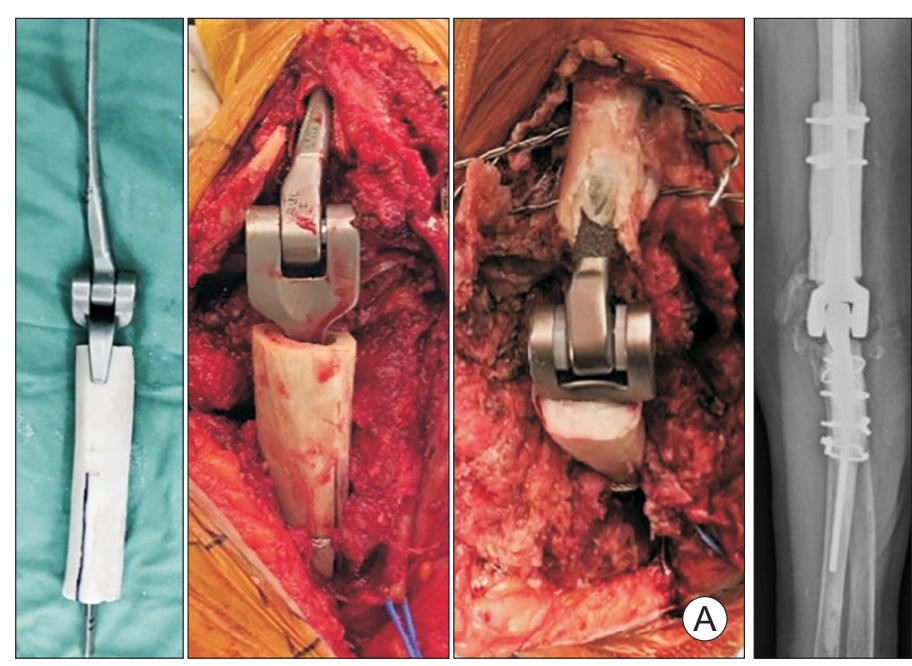

Fig. 5. Second stage of revision surgery using allograft-prosthetic composite (APC). (A) Modified type I APC used to manage bone defects. (B) Plain radiographs at the final follow-up. Bone union was observed between the host bone and the allograft bone. 
Kwak et al. Total Elbow Arthroplasty: Clinical Outcomes, Complications, and Revision Surgery

Clinics in Orthopedic Surgery • Vol. 11, No. 4, $2019 \bullet$ www.ecios.org

condyle fractures, Kirschner-wires are used to temporarily fix the fragments before reimplanting the components and cerclage wire is used for longitudinal fractures of the humerus or ulna. The humeral and ulnar shafts undergo extensive saline irrigation before the cement is introduced by using a third-generation cementing technique. Fluoroscopy is performed if the intramedullary canal of the humerus or ulna is difficult to locate. A longer component is preferred in all patients. ${ }^{37,65,92)}$

\section{Two-Stage Revision Surgery for Infectious Causes}

The first stage of surgery should focus on removing the infected tissues and the prosthesis. All cement and any tissue suspected of infection, including the synovial membrane, are completely and carefully removed. Samples of tissue surrounding the implants and joint fluid are cultured. The bones are windowed for well-fixed implants, and chlorhexidine solution diluted with $0.9 \%$ sodium chloride is used to irrigate the canals. In addition, an antibiotic cement spacer (5-g gentamicin, 1-g vancomycin, and 1-g ceftriaxone per 40-g cement) is introduced (Fig. 4). Patients receive the optimum dosage of intravenous antibiotics, on the basis of sensitivity tests, for $>6$ weeks until complete normalization of all serologic markers (white blood cell counts, erythrocyte sedimentation rates, and Creactive protein concentrations) has occurred. ${ }^{70,79,83)}$ The second stage of surgery centers on infection control and joint reconstruction with a new implant. After removal of the antibiotic cement spacer, tissue samples are acquired for follow-up sensitivity testing. All frozen intraoperative tissue samples are examined histologically to confirm the results from the real-time diagnostic tools. Acute inflammation is described as $\geq 5$ neutrophils per high-powered field, with any positive result nullifying the reimplantation procedure. $^{79,85}$

Morrey et al. ${ }^{90)}$ proposed three specific reconstruction techniques using allograft-prosthetic composite (APC) to manage bone defects. Type I reconstruction involves intussusception of the APC into the host bone (intussusception type) and is sometimes modified in a reverse fashion, such that the upper portion of the host bone is inserted by using the lower portion of the femur shaft as the allograft in case the host bone is too narrow to insert the allograft bone (Fig. 5A). Type II involves inserting the distal aspect of the stem into the host canal with a strutlike extension of the graft coadapted externally to the cortex while adapting a cortical strut graft. Type III comprises side-to-side contact between the cortices of the APC and the host bone. Wiring is frequently added to enhance the contact area and promote stable fixation between the host bones and the APC (Fig. 5B).

\section{CONCLUSIONS}

Although the annual incidence of TEAs performed for inflammatory arthritis is decreasing, RA still has been the most common indication with favorable outcomes. The indications for TEA have expanded to include traumarelated problems such as posttraumatic arthritis and unreconstructable elbow fracture. The high complication rate is still a challenge, but various efforts have been made in revision surgery, such as development of devices with different designs and surgical techniques.

\section{CONFLICT OF INTEREST}

No potential conflict of interest relevant to this article was reported.

\section{REFERENCES}

1. Dee R. Total replacement arthroplasty of the elbow for rheumatoid arthritis. J Bone Joint Surg Br. 1972;54(1):8895.

2. Broberg MA, Morrey BF. Results of delayed excision of the radial head after fracture. J Bone Joint Surg Am. 1986;68(5):669-74.

3. Giannicola G, Sacchetti FM, Antonietti G, Piccioli A, Postacchini R, Cinotti G. Radial head, radiocapitellar and total elbow arthroplasties: a review of recent literature. Injury. 2014;45(2):428-36.

4. Hackl M, Muller LP, Leschinger T, Wegmann K. Total elbow arthroplasty in traumatic and post-traumatic bone defects. Orthopade. 2017;46(12):990-1000.

5. Lami D, Chivot M, Caubere A, Galland A, Argenson JN. First-line management of distal humerus fracture by total elbow arthroplasty in geriatric traumatology: results in a 21-patient series at a minimum 2 years' follow-up. Orthop Traumatol Surg Res. 2017;103(6):891-7.

6. Mansat $\mathrm{P}$, Bonnevialle N, Rongieres $\mathrm{M}$, Bonnevialle $\mathrm{P}$; Bone, Joint Trauma Study Group (GETRAUM). The role of total elbow arthroplasty in traumatology. Orthop Traumatol Surg Res. 2014;100(6 Suppl):S293-8.

7. Pogliacomi F, Schiavi P, Defilippo M, et al. Total elbow arthroplasty following complex fractures of the distal humer- 
us: results in patients over 65 years of age. Acta Biomed. 2016;87(2):148-55.

8. Pooley J, Salvador Carreno J. Total elbow joint replacement for fractures in the elderly: functional and radiological outcomes. Injury. 2015;46 Suppl 5:S37-42.

9. Rajaee SS, Lin CA, Moon CN. Primary total elbow arthroplasty for distal humeral fractures in elderly patients: a nationwide analysis. J Shoulder Elbow Surg. 2016;25(11):1854-60.

10. Schoch BS, Werthel JD, Sanchez-Sotelo J, Morrey BF, Morrey $\mathrm{M}$. Total elbow arthroplasty for primary osteoarthritis. J Shoulder Elbow Surg. 2017;26(8):1355-9.

11. Brinkman JM, de Vos MJ, Eygendaal D. Failure mechanisms in uncemented Kudo type 5 elbow prosthesis in patients with rheumatoid arthritis: 7 of 49 ulnar components revised because of loosening after 2-10 years. Acta Orthop. 2007;78(2):263-70.

12. Kim HJ, Kim JY, Kee YM, Rhee YG. Total elbow arthroplasty under unfavourable soft tissue conditions. Int Orthop. 2018;42(2):367-74.

13. Kim JM, Mudgal CS, Konopka JF, Jupiter JB. Complications of total elbow arthroplasty. J Am Acad Orthop Surg. 2011;19(6):328-39.

14. Klug A, Gramlich Y, Buckup J, Schweigkofler U, Hoffmann $\mathrm{R}$, Schmidt-Horlohe K. Trends in total elbow arthroplasty: a nationwide analysis in Germany from 2005 to 2014. Int Orthop. 2018;42(4):883-9.

15. Park SE, Kim JY, Cho SW, Rhee SK, Kwon SY. Complications and revision rate compared by type of total elbow arthroplasty. J Shoulder Elbow Surg. 2013;22(8):1121-7.

16. Toulemonde J, Ancelin D, Azoulay V, Bonnevialle N, Rongieres M, Mansat P. Complications and revisions after semi-constrained total elbow arthroplasty: a mono-centre analysis of one hundred cases. Int Orthop. 2016;40(1):7380.

17. Welsink CL, Lambers KT, van Deurzen DF, Eygendaal D, van den Bekerom MP. Total elbow arthroplasty: a systematic review. JBJS Rev. 2017;5(7):e4.

18. Kudo H, Iwano K. Total elbow arthroplasty with a nonconstrained surface-replacement prosthesis in patients who have rheumatoid arthritis: a long-term follow-up study. J Bone Joint Surg Am. 1990;72(3):355-62.

19. Iwamoto T, Ikegami H, Suzuki T, et al. The history and future of unlinked total elbow arthroplasty. Keio J Med. 2018;67(2):19-25.

20. Kaufmann RA, D'Auria JL, Schneppendahl J. Total elbow arthroplasty: elbow biomechanics and failure. J Hand Surg Am. 2019;44(8):687-92.
21. Kodama A, Mizuseki T, Adachi N. Macroscopic investigation of failed Kudo type 5 total elbow arthroplasty. J Shoulder Elbow Surg. 2018;27(8):1380-5.

22. Kodama A, Mizuseki T, Adachi N. Kudo type-5 total elbow arthroplasty for patients with rheumatoid arthritis: a minimum ten-year follow-up study. Bone Joint J. 2017;99(6):818-23.

23. Ramirez MA, Cheung EV, Murthi AM. Revision total elbow arthroplasty. J Am Acad Orthop Surg. 2017;25(8):e166-74.

24. Figgie MP, Wright TM, Drinkwater D; Bioengineering Working Group. What design and material factors impact the wear and corrosion performance in total elbow arthroplasties? Clin Orthop Relat Res. 2014;472(12):3770-6.

25. Aldridge JM 3rd, Lightdale NR, Mallon WJ, Coonrad RW. Total elbow arthroplasty with the Coonrad/CoonradMorrey prosthesis: a 10- to 31-year survival analysis. J Bone Joint Surg Br. 2006;88(4):509-14.

26. King EA, Favre P, Eldemerdash A, Bischoff JE, Palmer M, Lawton JN. Physiological loading of the Coonrad/Morrey, Nexel, and Discovery elbow systems: evaluation by finite element analysis. J Hand Surg Am. 2019;44(1):61.e1-61.e9.

27. Jeon IH, Morrey BF, Sanchez-Sotelo J. Ulnar component surface finish influenced the outcome of primary CoonradMorrey total elbow arthroplasty. J Shoulder Elbow Surg. 2012;21(9):1229-35.

28. Shi LL, Zurakowski D, Jones DG, Koris MJ, Thornhill TS. Semiconstrained primary and revision total elbow arthroplasty with use of the Coonrad-Morrey prosthesis. J Bone Joint Surg Am. 2007;89(7):1467-75.

29. Pham TT, Delclaux S, Huguet S, Wargny M, Bonnevialle N, Mansat P. Coonrad-Morrey total elbow arthroplasty for patients with rheumatoid arthritis: 54 prostheses reviewed at 7 years' average follow-up (maximum, 16 years). J Shoulder Elbow Surg. 2018;27(3):398-403.

30. Kiran M, Jariwala A, Wigderowitz C. Medium term outcomes of primary and revision Coonrad-Morrey total elbow replacement. Indian J Orthop. 2015;49(2):233-8.

31. Barthel PY, Mansat P, Sirveaux F, Dap F, Mole D, Dautel G. Is total elbow arthroplasty indicated in the treatment of traumatic sequelae? 19 Cases of Coonrad-Morrey $\left({ }^{\circ}\right)$ reviewed at a mean follow-up of 5.2 years. Orthop Traumatol Surg Res. 2014;100(1):113-8.

32. Mansat P, Bonnevialle N, Rongieres M, Mansat M, Bonnevialle P. Experience with the Coonrad-Morrey total elbow arthroplasty: 78 consecutive total elbow arthroplasties reviewed with an average 5 years of follow-up. J Shoulder Elbow Surg. 2013;22(11):1461-8.

33. Mansat $\mathrm{P}$, Bonnevialle $\mathrm{N}$, Rongieres M, Mansat M, Bonn- 
Kwak et al. Total Elbow Arthroplasty: Clinical Outcomes, Complications, and Revision Surgery

Clinics in Orthopedic Surgery • Vol. 11, No. 4, $2019 \bullet$ www.ecios.org

evialle P; French Society for Shoulder and Elbow SOFEC. Results with a minimum of 10 years follow-up of the Coonrad/Morrey total elbow arthroplasty. Orthop Traumatol Surg Res. 2013;99(6 Suppl):S337-43.

34. Schneeberger AG, Meyer DC, Yian EH. Coonrad-Morrey total elbow replacement for primary and revision surgery: a 2- to 7.5-year follow-up study. J Shoulder Elbow Surg. 2007;16(3 Suppl):S47-54.

35. Gill DR, Morrey BF. The Coonrad-Morrey total elbow arthroplasty in patients who have rheumatoid arthritis: a ten to fifteen-year follow-up study. J Bone Joint Surg Am. 1998;80(9):1327-35.

36. Morrey BF, Bryan RS, Dobyns JH, Linscheid RL. Total elbow arthroplasty: a five-year experience at the Mayo Clinic. J Bone Joint Surg Am. 1981;63(7):1050-63.

37. Sundfeldt M, Carlsson LV, Johansson CB, Thomsen P, Gretzer C. Aseptic loosening, not only a question of wear: a review of different theories. Acta Orthop. 2006;77(2):17797.

38. Mukka S, Berg G, Hassany HR, Koye AK, Sjoden G, SayedNoor AS. Semiconstrained total elbow arthroplasty for rheumatoid arthritis patients: clinical and radiological results of 1-8 years follow-up. Arch Orthop Trauma Surg. 2015;135(5):595-600.

39. Alizadehkhaiyat O, Al Mandhari A, Sinopidis C, Wood A, Frostick S. Total elbow arthroplasty: a prospective clinical outcome study of Discovery Elbow System with a 4-year mean follow-up. J Shoulder Elbow Surg. 2015;24(1):52-9.

40. Hastings $\mathrm{H}$ 2nd. Minimally constrained elbow implant arthroplasty: the discovery elbow system. Tech Hand Up Extrem Surg. 2004;8(1):34-50.

41. de Vos MJ, Wagener ML, Hannink G, van der Pluijm M, Verdonschot N, Eygendaal D. Short-term clinical results of revision elbow arthroplasty using the Latitude total elbow arthroplasty. Bone Joint J. 2016;98(8):1086-92.

42. Wagener ML, de Vos MJ, Hannink G, van der Pluijm M, Verdonschot N, Eygendaal D. Mid-term clinical results of a modern convertible total elbow arthroplasty. Bone Joint J. 2015;97(5):681-8.

43. Prkic A, Welsink C, The B, van den Bekerom MP, Eygendaal D. Why does total elbow arthroplasty fail today? A systematic review of recent literature. Arch Orthop Trauma Surg. 2017;137(6):761-9.

44. Krukhaug Y, Hallan G, Dybvik E, Lie SA, Furnes ON. A survivorship study of 838 total elbow replacements: a report from the Norwegian Arthroplasty Register 1994-2016. J Shoulder Elbow Surg. 2018;27(2):260-9.

45. Hildebrand KA, Patterson SD, Regan WD, MacDermid JC,
King GJ. Functional outcome of semiconstrained total elbow arthroplasty. J Bone Joint Surg Am. 2000;82(10):137986.

46. Rangarajan R, Papandrea RF, Cil A. Distal humeral hemiarthroplasty versus total elbow arthroplasty for acute distal humeral fractures. Orthopedics. 2017;40(1):13-23.

47. Lovy AJ, Keswani A, Koehler SM, Kim J, Hausman M. Short-term complications of distal humerus fractures in elderly patients: open reduction internal fixation versus total elbow arthroplasty. Geriatr Orthop Surg Rehabil. 2016;7(1):39-44.

48. Lapner M, King GJ. Elbow arthroplasty for distal humeral fractures. Instr Course Lect. 2014;63:15-26.

49. Zhang D, Chen N. Total elbow arthroplasty. J Hand Surg Am. 2019;44(6):487-95.

50. Schoch B, Wong J, Abboud J, Lazarus M, Getz C, Ramsey M. Results of total elbow arthroplasty in patients less than 50 years old. J Hand Surg Am. 2017;42(10):797-802.

51. McKee MD, Veillette CJ, Hall JA, et al. A multicenter, prospective, randomized, controlled trial of open reduction: internal fixation versus total elbow arthroplasty for displaced intra-articular distal humeral fractures in elderly patients. J Shoulder Elbow Surg. 2009;18(1):3-12.

52. Barco R, Streubel PN, Morrey BF, Sanchez-Sotelo J. Total elbow arthroplasty for distal humeral fractures: a tenyear-minimum follow-up study. J Bone Joint Surg Am. 2017;99(18):1524-31.

53. Jenkins PJ, Watts AC, Norwood T, Duckworth AD, Rymaszewski LA, McEachan JE. Total elbow replacement: outcome of 1,146 arthroplasties from the Scottish Arthroplasty Project. Acta Orthop. 2013;84(2):119-23.

54. Fevang BT, Lie SA, Havelin LI, Skredderstuen A, Furnes O. Results after 562 total elbow replacements: a report from the Norwegian Arthroplasty Register. J Shoulder Elbow Surg. 2009;18(3):449-56.

55. Amirfeyz R, Blewitt N. Mid-term outcome of GSB-III total elbow arthroplasty in patients with rheumatoid arthritis and patients with post-traumatic arthritis. Arch Orthop Trauma Surg. 2009;129(11):1505-10.

56. Giannicola G, Scacchi M, Polimanti D, Cinotti G. Discovery elbow system: 2- to 5-year results in distal humerus fractures and posttraumatic conditions: a prospective study on 24 patients. J Hand Surg Am. 2014;39(9):1746-56.

57. Lenich A, Imhoff AB, Siebenlist S. Post-traumatic osteoarthritis of the elbow joint: endoprosthetic options in young patients. Orthopade. 2016;45(10):844-52

58. Celli A, Morrey BF. Total elbow arthroplasty in patients forty years of age or less. J Bone Joint Surg Am. 
Kwak et al. Total Elbow Arthroplasty: Clinical Outcomes, Complications, and Revision Surgery

Clinics in Orthopedic Surgery • Vol. 11, No. 4, $2019 \bullet$ www.ecios.org

\section{9;91(6):1414-8.}

59. Park JG, Cho NS, Song JH, Lee DS, Rhee YG. Clinical outcomes of semiconstrained total elbow arthroplasty in patients who were forty years of age or younger. J Bone Joint Surg Am. 2015;97(21):1781-91.

60. Kwak JM, Kholinne E, Sun Y, Lim S, Koh KH, Jeon IH. Clinical outcome of osteocapsular arthroplasty for primary osteoarthritis of the elbow: comparison of arthroscopic and open procedure. Arthroscopy. 2019;35(4):1083-9.

61. Kwak JM, Kholinne E, Sun Y, Kim MS, Koh KH, Jeon IH. Clinical results of revision total elbow arthroplasty: comparison of infected and non-infected total elbow arthroplasty. Int Orthop. 2019;43(6):1421-7.

62. Farnsworth CW, Schott EM, Benvie AM, et al. Obesity/ type 2 diabetes increases inflammation, periosteal reactive bone formation, and osteolysis during Staphylococcus aureus implant-associated bone infection. J Orthop Res. 2018;36(6):1614-23.

63. Perretta D, van Leeuwen WF, Dyer G, Ring D, Chen N. Risk factors for reoperation after total elbow arthroplasty. J Shoulder Elbow Surg. 2017;26(5):824-9.

64. Griffin JW, Werner BC, Gwathmey FW, Chhabra AB. Obesity is associated with increased postoperative complications after total elbow arthroplasty. J Shoulder Elbow Surg. 2015;24(10):1594-601.

65. Geurts EJ, Viveen J, van Riet RP, Kodde IF, Eygendaal D. Outcomes after revision total elbow arthroplasty: a systematic review. J Shoulder Elbow Surg. 2019;28(2):381-6.

66. Parvizi J, Shohat N, Gehrke T. Prevention of periprosthetic joint infection: new guidelines. Bone Joint J. 2017;99(4 Supple B):3-10.

67. Ting NT, Della Valle CJ. Diagnosis of periprosthetic joint infection-an algorithm-based approach. J Arthroplasty. 2017;32(7):2047-50.

68. Somerson JS, Morrey ME, Sanchez-Sotelo J, Morrey BF. Diagnosis and management of periprosthetic elbow infection. J Bone Joint Surg Am. 2015;97(23):1962-71.

69. Drago L, De Vecchi E, Bortolin M, Zagra L, Romano CL, Cappelletti L. Epidemiology and antibiotic resistance of late prosthetic knee and hip infections. J Arthroplasty. 2017;32(8):2496-500.

70. Henderson RA, Austin MS. Management of periprosthetic joint infection: the more we learn, the less we know. J Arthroplasty. 2017;32(7):2056-9.

71. Pruzansky JS, Bronson MJ, Grelsamer RP, Strauss E, Moucha CS. Prevalence of modifiable surgical site infection risk factors in hip and knee joint arthroplasty patients at an urban academic hospital. J Arthroplasty. 2014;29(2):272-6.
72. Streubel PN, Simone JP, Morrey BF, Sanchez-Sotelo J, Morrey ME. Infection in total elbow arthroplasty with stable components: outcomes of a staged surgical protocol with retention of the components. Bone Joint J. 2016;98(7):97683.

73. Kok TW, Agrawal N, Sathappan SS, Chen WK. Risk factors for early implant-related surgical site infection. J Orthop Surg (Hong Kong). 2016;24(1):72-6.

74. Spormann C, Achermann Y, Simmen BR, et al. Treatment strategies for periprosthetic infections after primary elbow arthroplasty. J Shoulder Elbow Surg. 2012;21(8):992-1000.

75. Pope D, Scaife SL, Tzeng TH, Vasdev S, Saleh KJ. Impact of diabetes on early postoperative outcomes after total elbow arthroplasty. J Shoulder Elbow Surg. 2015;24(3):348-52.

76. Toor AS, Jiang JJ, Shi LL, Koh JL. Comparison of perioperative complications after total elbow arthroplasty in patients with and without diabetes. J Shoulder Elbow Surg. 2014;23(11):1599-606.

77. Mraovic B, Suh D, Jacovides C, Parvizi J. Perioperative hyperglycemia and postoperative infection after lower limb arthroplasty. J Diabetes Sci Technol. 2011;5(2):412-8.

78. Yoon HK, Cho SH, Lee DY, et al. A review of the literature on culture-negative periprosthetic joint infection: epidemiology, diagnosis and treatment. Knee Surg Relat Res. 2017;29(3):155-64.

79. Peach CA, Nicoletti S, Lawrence TM, Stanley D. Two-stage revision for the treatment of the infected total elbow arthroplasty. Bone Joint J. 2013;95(12):1681-6.

80. Rudge WB, Eseonu K, Brown M, et al. The management of infected elbow arthroplasty by two-stage revision. J Shoulder Elbow Surg. 2018;27(5):879-86.

81. Wagner ER, Ransom JE, Kremers HM, Morrey M, Sanchez-Sotelo J. Comparison of the hospital costs for twostage reimplantation for deep infection, single-stage revision and primary total elbow arthroplasty. Shoulder Elbow. 2017;9(4):279-84.

82. Zmistowski B, Pourjafari A, Padegimas EM, et al. Treatment of periprosthetic joint infection of the elbow: 15-year experience at a single institution. J Shoulder Elbow Surg. 2018;27(9):1636-41.

83. Osmon DR, Berbari EF, Berendt AR, et al. Diagnosis and management of prosthetic joint infection: clinical practice guidelines by the Infectious Diseases Society of America. Clin Infect Dis. 2013;56(1):e1-25.

84. Choi HR, Kwon YM, Freiberg AA, Nelson SB, Malchau H. Periprosthetic joint infection with negative culture results: clinical characteristics and treatment outcome. J Arthroplasty. 2013;28(6):899-903. 
Kwak et al. Total Elbow Arthroplasty: Clinical Outcomes, Complications, and Revision Surgery

Clinics in Orthopedic Surgery • Vol. 11, No. 4, 2019• www.ecios.org

85. Parvizi J, Adeli B, Zmistowski B, Restrepo C, Greenwald AS. Management of periprosthetic joint infection: the current knowledge: AAOS exhibit selection. J Bone Joint Surg Am. 2012;94(14):e104.

86. Morrey BF, Bryan RS. Infection after total elbow arthroplasty. J Bone Joint Surg Am. 1983;65(3):330-8.

87. Zhou H, Orvets ND, Merlin G, et al. Total elbow arthroplasty in the United States: evaluation of cost, patient demographics, and complication rates. Orthop Rev (Pavia). 2016;8(1):6113.

88. Rhee YG, Cho NS, Parke CS. Impaction grafting in revision total elbow arthroplasty due to aseptic loosening and bone loss. J Bone Joint Surg Am. 2013;95(11):e741-7.

89. Goldberg SH, Urban RM, Jacobs JJ, King GJ, O'Driscoll SW, Cohen MS. Modes of wear after semiconstrained total elbow arthroplasty. J Bone Joint Surg Am. 2008;90(3):60919.

90. Morrey ME, Sanchez-Sotelo J, Abdel MP, Morrey BF. Allograft-prosthetic composite reconstruction for massive bone loss including catastrophic failure in total elbow arthroplasty. J Bone Joint Surg Am. 2013;95(12):1117-24.

91. King GJ, Adams RA, Morrey BF. Total elbow arthroplasty: revision with use of a non-custom semiconstrained prosthesis. J Bone Joint Surg Am. 1997;79(3):394-400.

92. Sanchez-Sotelo J, O'Driscoll S, Morrey BF. Periprosthetic humeral fractures after total elbow arthroplasty: treatment with implant revision and strut allograft augmentation. J Bone Joint Surg Am. 2002;84(9):1642-50.

93. Celli A, Arash A, Adams RA, Morrey BF. Triceps insufficiency following total elbow arthroplasty. J Bone Joint Surg
Am. 2005;87(9):1957-64.

94. Voloshin I, Schippert DW, Kakar S, Kaye EK, Morrey BF. Complications of total elbow replacement: a systematic review. J Shoulder Elbow Surg. 2011;20(1):158-68.

95. Dachs RP, Fleming MA, Chivers DA, et al. Total elbow arthroplasty: outcomes after triceps-detaching and tricepssparing approaches. J Shoulder Elbow Surg. 2015;24(3):33947.

96. Solarz MK, Patel MK, Struk AM, et al. A clinical comparison of triceps-sparing and triceps-detaching approaches for revision total elbow arthroplasty. J Hand Surg Am. 2019 Jun 18 [Epub]. https://doi.org/10.1016/j.jhsa.2019.05.002.

97. Lee H, Vaichinger AM, O’Driscoll SW. Component fracture after total elbow arthroplasty. J Shoulder Elbow Surg. 2019;28(8):1449-56.

98. Dachs RP, Vrettos BC, Chivers DA, Du Plessis JP, Roche SJ. Outcomes after ulnar nerve in situ release during total elbow arthroplasty. J Hand Surg Am. 2015;40(9):1832-7.

99. Morrey BF, Bryan RS. Revision total elbow arthroplasty. J Bone Joint Surg Am. 1987;69(4):523-32.

100. Cheung EV, O’Driscoll SW. Total elbow prosthesis loosening caused by ulnar component pistoning. J Bone Joint Surg Am. 2007;89(6):1269-74.

101. Renfree KJ, Dell PC, Kozin SH, Wright TW. Total elbow arthroplasty with massive composite allografts. J Shoulder Elbow Surg. 2004;13(3):313-21.

102. O’Driscoll SW, King GJ. Treatment of instability after total elbow arthroplasty. Orthop Clin North Am. 2001;32(4):679-95. 